\title{
[3+2] Fragmentation of a Pentaphosphido Ligand by Cyanide**
}

\author{
Christian M. Hoidn, Thomas M. Maier, Karolina Trabitsch, Jan J. Weigand, and Robert Wolf*
}

\begin{abstract}
The activation of white phosphorus $\left(P_{4}\right)$ by transition-metal complexes has been studied for several decades, but the functionalization and release of the resulting (organo)phosphorus ligands has rarely been achieved. Herein we describe the formation of rare diphosphan-1-ide anions from a $P_{5}$ ligand by treatment with cyanide. Cobalt diorganopentaphosphido complexes have been synthesized by a stepwise reaction sequence involving a low-valent diimine cobalt complex, white phosphorus, and diorganochlorophosphanes. The reactions of the complexes with tetraalkylammonium or potassium cyanide afford a cyclotriphosphido cobaltate anion 5 and 1-cyanodiphosphan-1-ide anions $\left[\mathrm{R}_{2} P P C N\right]^{-}(\mathbf{6}-\boldsymbol{R})$. The molecular structure of a related product 7 suggests a novel reaction mechanism, where coordination of the cyanide anion to the cobalt center induces a ligand rearrangement. This is followed by nucleophilic attack of a second cyanide anion at a phosphorus atom and release of the $P_{2}$ fragment.
\end{abstract}

ver the past few decades, studies on the activation of white phosphorus have produced numerous early and late-transition-metal polyphosphido complexes. ${ }^{[1]}$ The functionalization of the polyphosphorus ligands in such compounds with electrophiles and/or nucleophiles is potentially an elegant and atom-economical route to unique phosphorus compounds. However, such transition-metal-mediated $\mathrm{P}_{4}$ functionalizations and, in particular, the release of useful phosphorus building blocks from the metal are generally difficult to achieve because of the low reactivity of many known polyphosphido compounds toward electrophiles. ${ }^{[2]}$ Rare examples of successful electrophilic functionalization reactions are shown in Scheme 1 a. Peruzzini, Stoppioni, and coworkers reported the methylation of a cyclo- $\mathrm{P}_{3}$ ligand at Group 9 metal cations, ${ }^{[3]}$ Cummins and co-workers described

[*] C. M. Hoidn, T. M. Maier, K. Trabitsch, Prof. Dr. R. Wolf University of Regensburg Institute of Inorganic Chemistry 93040 Regensburg (Germany) E-mail: robert.wolf@ur.de

Prof. Dr. J. J. Weigand

TU Dresden, Faculty of Chemistry and Food Chemistry 01062 Dresden (Germany)

E-mail: jan.weigand@tu-dresden.de

[**] A previous version of this manuscript has been deposited on a preprint server (https://doi.org/10.26434/chemrxiv.8868701.v1).

(1) Supporting information and the ORCID identification numbers for

(iD) some of the authors of this article can be found under: https://doi.org/10.1002/anie.201908744.

of (c) 2019 The Authors. Published by Wiley-VCH Verlag GmbH \& Co. $\mathrm{KGaA}$. This is an open access article under the terms of the Creative Commons Attribution Non-Commercial License, which permits use, distribution and reproduction in any medium, provided the original work is properly cited, and is not used for commercial purposes.

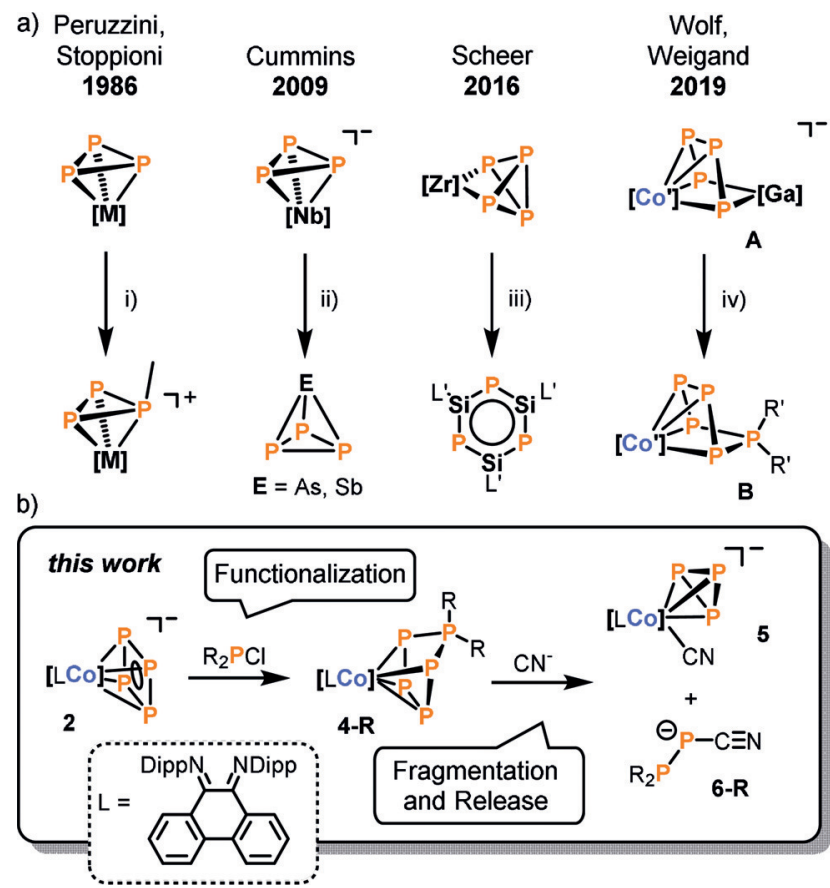

Scheme 1. a) Examples of established functionalizations of polyphosphorus ligands: i) $+\mathrm{CF}_{3} \mathrm{SO}_{3} \mathrm{Me}$ or $+\left[\mathrm{Me}_{3} \mathrm{O}\right] \mathrm{BF}_{4} /-\mathrm{Me}_{2} \mathrm{O}$; $[\mathrm{M}]=[\mathrm{M}-$ (triphos)] $\left(\mathrm{M}=\mathrm{Co}, \mathrm{Rh}, \mathrm{Ir}\right.$, triphos $\left.\left.=\mathrm{CH}_{3} \mathrm{C}\left(\mathrm{CH}_{2} \mathrm{PPh}_{2}\right)_{3}\right) ; \mathrm{ii}\right)+\mathrm{AsCl}_{3}$ or $+\mathrm{SbCl}_{3} /-\mathrm{NaCl},-[\mathrm{Nb}] \mathrm{Cl}_{2}(\mathrm{thf}) ;[\mathrm{Nb}]=\left[\mathrm{Nb}(\mathrm{ODipp})_{3}\right](\mathrm{Dipp}=2,6-$ $\left.\left.i \mathrm{Pr}_{2} \mathrm{C}_{6} \mathrm{H}_{3}\right) ; \mathrm{iii}\right)+\left[\left(\mathrm{L}^{\prime}\right) \mathrm{SiCl}\right] /-[\mathrm{Zr}] \mathrm{Cl}_{2}, \mathrm{~L}^{\prime}=\mathrm{PhC}(\mathrm{N} t \mathrm{Bu})_{2}$;

$\left.[\mathrm{Zr}]=\left[\left(\mathrm{C}_{5} \mathrm{H}_{3} t \mathrm{Bu}_{2}\right)_{2} \mathrm{Zr}\right] ; \mathrm{iv}\right)+\mathrm{R}_{2}^{\prime} \mathrm{PCl} /-\mathrm{KCl},-[\mathrm{Ga}] ;[\mathrm{Ga}]=[\mathrm{Ga}(\mathrm{CH}-$ $\left.\left.(\mathrm{CMeNDipp})_{2}\right)\right],\left[\mathrm{Co}^{\prime}\right]=\left[\left({ }^{\mathrm{Mes}} \mathrm{BIAN}\right) \mathrm{Co}\right], \mathrm{BIAN}=1,2$-bis (arylimino)acenaphthene; $\mathrm{R}^{\prime}=\mathrm{Cy}, i \mathrm{Pr}, t \mathrm{Bu}$. b) Ligand functionalization and subsequent fragmentation reactions affording new phosphorus compounds ( $\mathrm{L}=\mathrm{PHDI}=$ bis(2,6-diisopropylphenyl) phenanthrene-9,10-diimine; $\left.\mathrm{R}=\mathrm{Cy}, \mathrm{tBu}, \mathrm{Ph}, \mathrm{Mes}, \mathrm{N}(\mathrm{Pr})_{2}\right)$.

the remarkable synthesis of $\mathrm{EP}_{3}(\mathrm{E}=\mathrm{As}, \mathrm{Sb})$ molecules from $\left[\mathrm{Nb}(\mathrm{ODipp})_{3}\left(\eta^{3}-\mathrm{P}_{3}\right)\right]^{-}\left(\mathrm{Dipp}=2,6-i \mathrm{Pr}_{2} \mathrm{C}_{6} \mathrm{H}_{3}\right)$ and $\mathrm{ECl}_{3},{ }^{[4]}$ and quite recently Scheer and co-workers disclosed the synthesis of a phosphorus-silicon analogue of benzene from a tetraphosphidozirconium complex. ${ }^{[5]}$ Recent studies from our groups have shown that the heterodinuclear cobalt-gallium species A can be successfully applied for the construction of novel alkyl-substituted pentaphosphido complexes $\mathbf{B}^{\left[{ }^{[6]}\right.}$ However, the synthesis of $\mathbf{A}$ is cumbersome, and the reaction properties of B-type species have, therefore, not been explored.

Here we present a much more facile synthesis of diorganopentaphosphido ligands and their fragmentation into $\mathrm{P}_{2}$ and $\mathrm{P}_{3}$ units (Scheme $1 \mathrm{~b}$ ). The bis(2,6-diisopropylphenyl)phenanthrene-9,10-diimine (PHDI) complex [K(18c$\left.6)(\text { thf })_{1.5}\right]\left[(\mathrm{PHDI}) \mathrm{Co}\left(\eta^{4}-1,5-\mathrm{cod}\right)\right] \quad([\mathrm{K}(18 \mathrm{c}-6)] \mathbf{1} ; \quad 18 \mathrm{c}-6=$ [18]crown-6, cod = cycloocta-1,5-diene) enables the straightforward, high-yielding synthesis of an anionic cyclo- $\mathrm{P}_{4}$ cobalt 


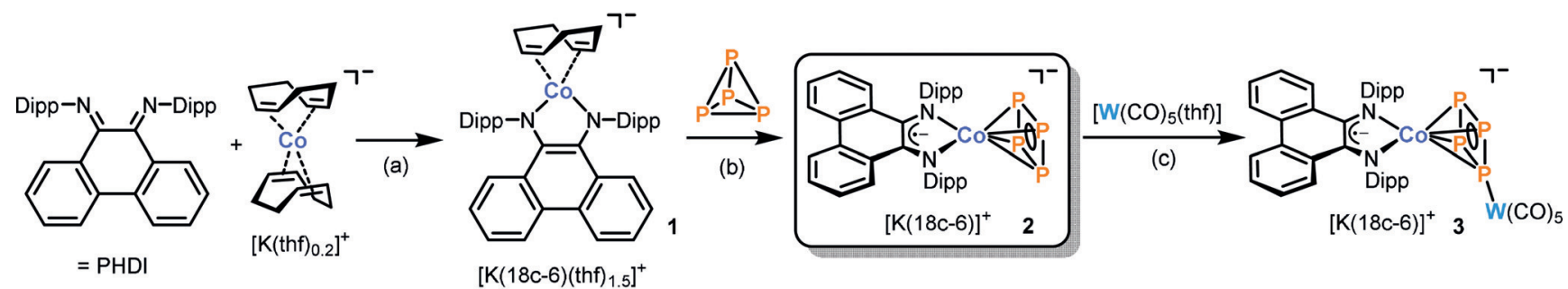

Scheme 2. Synthesis of compounds $[K(18 c-6)] 1-3(18 c-6=[18]$ crown- 6$)$; reagents and by-products: $a)+18 c-6 /-1,5-c o d ; b)+P_{4} /-1,5-c o d$; c) $+\left[\mathrm{W}(\mathrm{CO})_{5}(\mathrm{thf})\right] /-$ thf; yields: $[\mathrm{K}(18 \mathrm{c}-6)] 176 \%,[\mathrm{~K}(18 \mathrm{c}-6)] 280 \%,[\mathrm{~K}(18 \mathrm{c}-6)] 332 \%$.

complex 2, which is readily functionalized with dialkyl-, diaryl-, and diaminylphosphino groups. Cyanide anions cleave the resulting pentaphosphorus unit into a cyclo- $\mathrm{P}_{3}$ complex 5 and 1-cyanodiphosphan-1-ide anions $\left[\mathrm{R}_{2} \mathrm{PPCN}\right]$ $(\mathbf{6}-\mathbf{R}){ }^{[7]}$

Our investigation commenced with the synthesis of the new $\alpha$-diimine complex $[\mathrm{K}(18 \mathrm{c}-6)] \mathbf{1}$ by ligand exchange of the 1,5-cod in $\left[\mathrm{K}(\mathrm{thf})_{0.2}\right]\left[\mathrm{Co}\left(\eta^{4}-1,5-\mathrm{cod}\right)_{2}\right]$ with PHDI followed by the addition of [18]crown-6 (Scheme 2, reaction a). Filtration and crystallization from $\mathrm{THF} / n$-hexane afforded analytically pure, dark-green crystals of $[\mathrm{K}(18 \mathrm{c}-6)] \mathbf{1}$ in good yield. The NMR spectra of 1 compare well with those of the related 1,2bis(arylimino)acenaphthene ( $\left.{ }^{\mathrm{Ar}} \mathrm{BIAN}\right)$ complexes $\mathrm{K}\left[\mathrm{Co}\left(\eta^{4}-\right.\right.$ 1,5-cod $)\left({ }^{\text {Ar BIAN })](A r=D i p p, ~ M e s) ~} .^{[6,8]}\right.$

Next, the reaction of $[\mathrm{K}(18 \mathrm{c}-6)] \mathbf{1}$ with white phosphorus was examined (Scheme 2, reaction b). Monitoring of the reaction by ${ }^{31} \mathrm{P}\left\{{ }^{1} \mathrm{H}\right\} \mathrm{NMR}$ spectroscopy showed quantitative conversion into $[\mathrm{K}(18 \mathrm{c}-6)]\left[(\mathrm{PHDI}) \mathrm{Co}\left(\eta^{4}-c y c l o-\mathrm{P}_{4}\right)\right]([\mathrm{K}(18 \mathrm{c}-$ 6)]2) at room temperature. Crystallization from toluene/nhexane gave $[\mathrm{K}(18 \mathrm{c}-6)] 2$ as dark-turquoise crystals in up to $80 \%$ yield (corresponding to $>1.5 \mathrm{~g}$ of pure product). The ${ }^{31} \mathrm{P}\left\{{ }^{1} \mathrm{H}\right\}$ NMR spectrum of $[\mathrm{K}(18 \mathrm{c}-6)] 2$ in $\left[\mathrm{D}_{8}\right] \mathrm{THF}$ shows a sharp singlet at $\delta=136.5 \mathrm{ppm}$ (compare with the chemical shifts of $\delta=175.2 \mathrm{ppm}$ observed for $\left[\left(\eta^{5}-\mathrm{Cp}^{t \mathrm{Bu} 3}\right) \operatorname{Co}\left(\eta^{4}-\mathrm{P}_{4}\right)\right]^{[12]}$ $\left(\mathrm{Cp}^{t \mathrm{Bu} 3}=\mathrm{C}_{5} \mathrm{H}_{2} t \mathrm{Bu}_{3}\right)$ and $\delta=114.1 \mathrm{ppm}$ for $\left[\left(\eta^{5}-\mathrm{Cp}^{\mathrm{Ar}}\right) \mathrm{Fe}\left(\eta^{4}-\right.\right.$ $\left.\left.\mathrm{P}_{4}\right)\right]^{-}\left(\mathrm{Cp}^{\mathrm{Ar}}=\mathrm{C}_{5}\left(\mathrm{C}_{6} \mathrm{H}_{4}-4-\mathrm{Et}\right)_{5}\right) \cdot{ }^{[10]}$ A single-crystal X-ray diffraction (XRD) analysis clearly revealed the presence of a bidentate PHDI ligand and a terminal $\eta^{4}$-coordinated cyclo$\mathrm{P}_{4}$ unit. A more detailed interpretation of the structure was unfortunately prevented by heavy disorder within the cyclo$\mathrm{P}_{4}$ unit (see Figure S57 in the Supporting Information for further details). However, the single-crystal X-ray diffraction analysis of an adduct $[\mathrm{K}(18 \mathrm{c}-6)]\left[(\mathrm{PHDI}) \mathrm{Co}\left(\mu^{2}: \eta^{1}, \eta^{4}-\mathrm{P}_{4}\right) \mathrm{W}\right.$ $\left.(\mathrm{CO})_{5}\right]([\mathrm{K}(18 \mathrm{c}-6)] 3$; Scheme 2 , reaction $\mathrm{c})$, formed quantitatively from $[\mathrm{K}(18 \mathrm{c}-6)] 2$ and $\left[\mathrm{W}(\mathrm{CO})_{5}(\mathrm{thf})\right]$ according to monitoring by ${ }^{31} \mathrm{P}$ NMR spectroscopy, revealed an ordered structure (see Figure S58). An almost square, $\eta^{4}$-coordinated cyclo $-\mathrm{P}_{4}$ unit similar to those in related complexes is observed. ${ }^{[9-12]}$ The $\mathrm{P}-\mathrm{P}$ bond lengths (2.132(4) to 2.173(5) $\AA$, mean: $2.147(7) \AA)$ are in-between the values expected for $\mathrm{P}-$ $\mathrm{P}(2.22 \AA)$ and $\mathrm{P}=\mathrm{P}$ bonds $(2.04 \AA)$ and suggest the presence of a $\left(\text { cyclo }-\mathrm{P}_{4}\right)^{2-}$ dianion. ${ }^{[11 e, 13]}$ The $\mathrm{C}-\mathrm{C}$ and $\mathrm{C}-\mathrm{N}$ bond lengths in the PHDI backbone $(\mathrm{C}-\mathrm{C} 1.42(1) \AA$ (1) $\AA$ ) indicate the presence of PHDI in its radical anionic form.${ }^{[14]}$ Further details of the characterization of $[\mathrm{K}(18 \mathrm{c}-6)] \mathbf{3}$, including a discussion of the NMR data, are given in the Supporting Information.
In general, mononuclear cyclo- $\mathrm{P}_{4}$ complexes are still surprisingly rare. Besides two recently published iron complexes, ${ }^{[9,10]}$ only examples with early transition metals (e.g. V, $\mathrm{Nb}, \mathrm{Ta}, \mathrm{Mo})$ are known to date. ${ }^{[11]}$ A recently reported, neutral cyclo- $\mathrm{P}_{4}$ cobalt sandwich complex $\left[\left(\eta^{5}-\mathrm{Cp}^{t \mathrm{Bu} 3}\right) \mathrm{Co}\left(\eta^{4}-\right.\right.$ $\left.\mathrm{P}_{4}\right)$ ] described by Scheer and co-workers is unstable at room temperature and only accessible in low yields after column chromatography. ${ }^{[12]}$ In contrast, $[\mathrm{K}(18 \mathrm{c}-6)] \mathbf{2}$ is indefinitely stable at room temperature, both as a solid and in solution.

This finding suggests $[\mathrm{K}(18 \mathrm{c}-6)] 2$ to be an excellent precursor for $\mathrm{P}-\mathrm{P}$ bond-forming reactions with diorganochlorophosphanes. Reactions with $\mathrm{R}_{2} \mathrm{PCl}(\mathrm{R}=\mathrm{Cy}, t \mathrm{Bu}, \mathrm{Ph}$, Mes, $\mathrm{N}(i \mathrm{Pr})_{2}$; Scheme 3$)$ proceeded quantitatively $\left({ }^{31} \mathrm{P} \mathrm{NMR}\right.$

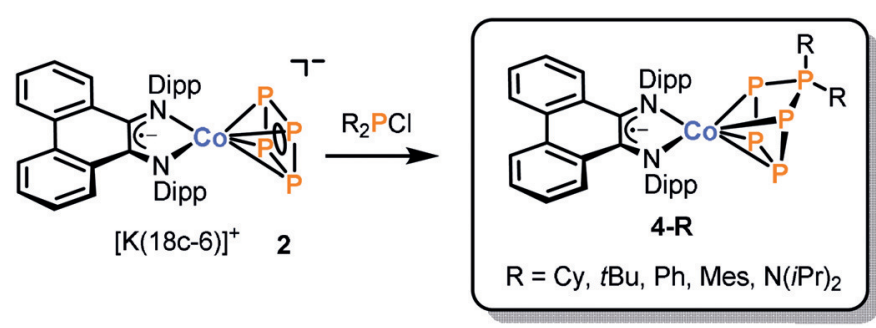

Scheme 3. Functionalization of the $\mathrm{P}_{4}$ unit in $\mathbf{2}$ by various chlorophosphanes to afford the pentaphosphido complexes $4-\mathbf{R}$; reagents and byproducts: $+\mathrm{R}_{2} \mathrm{PCl} /-\mathrm{KCl},-18 \mathrm{c}-6$; yields range from 33 to $77 \%$.

monitoring) to afford pentaphosphido complexes $\left[(\mathrm{PHDI}) \mathrm{Co}\left(\eta^{4}-\mathrm{P}_{5} \mathrm{R}_{2}\right)\right]$ (4-R), which were isolated as darkblue crystals in up to $77 \%$ yield by a convenient work-up procedure. Analogous reactions with $\mathrm{K}_{2}\left[\mathrm{Co}_{2}\left(\mu^{2}: \eta^{4}, \eta^{4}-\mathrm{P}_{4}\right)\right.$ $\left({ }^{\text {Dipp }} \mathrm{BIAN}\right)_{2}$ ] were observed to lead only to unproductive outer-sphere electron-transfer reactions. ${ }^{[8]}$

Complexes 4-R are isostructural and resemble those of the recently reported species $\left[\left({ }^{\mathrm{Mes}} \mathrm{BIAN}\right) \mathrm{Co}\left(\eta^{4}-\mathrm{P}_{5} \mathrm{R}_{2}\right)\right](\mathbf{B}, \mathrm{R}=$ $i \mathrm{Pr}, t \mathrm{Bu}, \mathrm{Cy}$; see Scheme $1 \mathrm{a}) .^{[6]}$ The molecular structure of 4$\boldsymbol{t} \mathbf{B u}$ is shown as an example in Figure $1 \mathrm{a}$; the remaining structures with $\mathrm{R}=\mathrm{Cy}, \mathrm{Ph}, \mathrm{Mes}$, and $\mathrm{NiPr}$ are given in the Supporting Information. The $\eta^{4}$-cyclo- $\mathrm{P}_{5} \mathrm{R}_{2}$ ligands show an envelope conformation with $\mathrm{P}-\mathrm{P}$ bond lengths ranging from 2.1197(2) to 2.182(1) $\AA$, which indicates some delocalized character. ${ }^{[13]}$ The $\mathrm{C}-\mathrm{C}$ and $\mathrm{C}-\mathrm{N}$ distances in $\mathbf{4}-\mathbf{R}$ suggest the presence of $\mathrm{PHDI}^{-}$radical anions. ${ }^{[6,14]}$ The ${ }^{31} \mathrm{P}\left\{{ }^{1} \mathrm{H}\right\}$ NMR spectra recorded in $\mathrm{C}_{6} \mathrm{D}_{6}$ show an $\mathrm{AMM}^{\prime} \mathrm{XX}^{\prime}$ spin system in each case (see Figure $1 \mathrm{~b}$ for the spectrum of $\mathbf{4 - t} \mathbf{B} \mathbf{B}$ as an example). ${ }^{[6]}$ The chemical shift of the tetracoordinate phosphorus atoms $\mathrm{P}_{\mathrm{A}}$ varies with the substituent (e.g. $\delta=$ 
a)

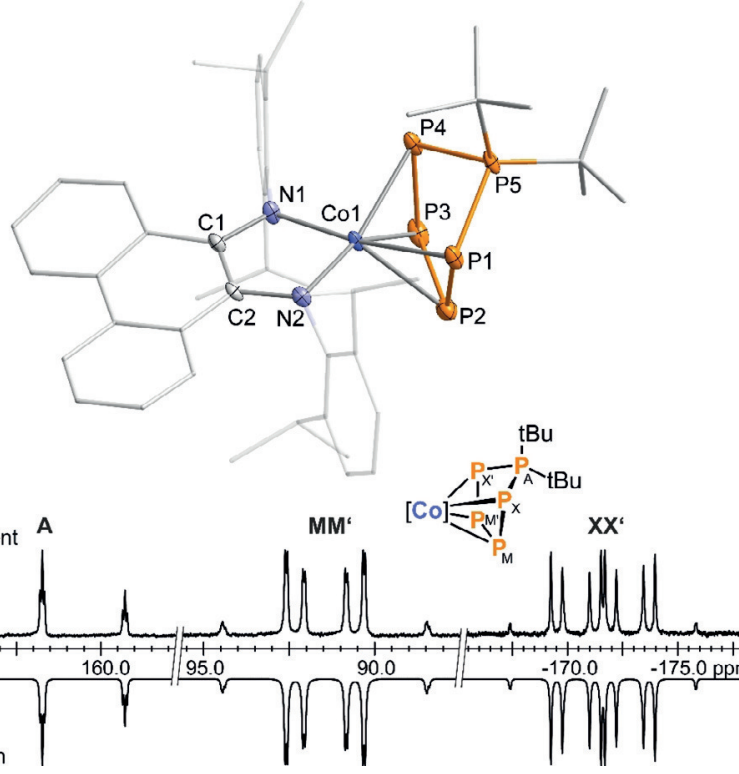

Figure 1. a) Solid-state molecular structure of $\left[(\mathrm{PHDI}) \mathrm{Co}\left(\eta^{4}-\mathrm{P}_{5} t \mathrm{Bu}_{2}\right)\right]$ (4-tBu). Hydrogen atoms are omitted for clarity and thermal ellipsoids are drawn at the $60 \%$ probability level. Selected bond lengths $[\AA]$ and angles [ [ ]: P1-P2 2.1410(9), P1-P5 2.1596(8), P2-P3 2.132(1), P3-P4 2.1394(9), P4-P5 2.1487(9), Co1-P1 2.3687(7), Co1-P2 2.3463(7), Co1-P3 2.3236(7), Co1-P4 $2.3928(7)$, Col-N1 1.893(2), Col-N2 $1.896(2), \mathrm{C} 1-\mathrm{N} 11.360(3), \mathrm{C} 2-\mathrm{N} 21.360(3), \mathrm{C} 1-\mathrm{C} 2$ 1.427(3); P1-P2-P3 103.63(3), P2-P3-P4 105.11(4), P3-P4-P5 100.41(4), P4-P5-P1 95.69(3), P5-P1-P2 100.63(3). b) Section of the ${ }^{31} P\left\{{ }^{1} H\right\}$ NMR spectrum of 4-tBu with nuclei assigned to an $\mathrm{AMM}^{\prime} X \mathrm{X}^{\prime}$ spin system; experimental (top); simulation (bottom): $\delta\left(\mathrm{P}_{\mathrm{A}}\right)=161.7 \mathrm{ppm}, \delta\left(\mathrm{P}_{\mathrm{MM}^{\prime}}\right)=91.4 \mathrm{ppm}, \delta\left(\mathrm{P}_{\mathrm{XX}^{\prime}}\right)$ $=-171.6 \mathrm{ppm},{ }^{1} J_{\mathrm{AX}}={ }^{1} \mathrm{~J}_{\mathrm{AX}}=-396.3 \mathrm{~Hz},{ }^{1} J_{\mathrm{MX}}={ }^{1} J_{\mathrm{M}^{\prime} \mathrm{X}^{\prime}}=-404.1 \mathrm{~Hz}$, ${ }^{1} J_{M^{\prime}}=-383.6 \mathrm{~Hz},{ }^{2} J_{M^{\prime}}={ }^{2} J_{M^{\prime} x}=35.9 \mathrm{~Hz},{ }^{2} J_{\mathrm{AM}}={ }^{2} J_{\mathrm{AM}^{\prime}}=10.9 \mathrm{~Hz}$,

${ }^{2} J_{x^{\prime}}=-4.9 \mathrm{~Hz}$; the spectra of the residual compounds $4-\mathbf{R}$ are very similar (see the Supporting Information for further details); $[\mathrm{Co}]=(\mathrm{PH}$ DI)Co.

$161.7 \mathrm{ppm}$ for $\mathbf{4 - t} \mathbf{B u}$ versus $\delta=84.3 \mathrm{ppm}$ for $\mathbf{4 - M e s )}$, while the remaining data are similar to those observed for complexes $\mathbf{B}$ shown in Scheme 1.

Having substantial quantities of cyclo- $\mathrm{P}_{5} \mathrm{R}_{2}$ complexes 4$\mathbf{R}\left(\mathrm{R}=\mathrm{Cy}, t \mathrm{Bu}, \mathrm{Ph}, \mathrm{Mes}, \mathrm{N}(i \mathrm{Pr})_{2}\right)$ in hand, reactions of these compounds with nucleophiles were examined in the hope of releasing the pentaphosphorus fragment. Although initial reactions with carbon monoxide, cyclohexylisonitrile, and $N, N^{\prime}$-diisopropyl-4,5-dimethylimidazolin-2-ylidene gave intractable mixtures, the reaction with cyanide salts $[\mathrm{M}] \mathrm{CN}$ $\left([\mathrm{M}]=\left[n \mathrm{Bu}_{4} \mathrm{~N}\right]^{+},\left[\mathrm{Et}_{4} \mathrm{~N}\right]^{+},[\mathrm{K}(18 \mathrm{c}-6)]^{+} ;\right.$Scheme 4, reaction a) was far more promising. ${ }^{[15]}$ An immediate color change from dark blue to dark purple-blue occured upon addition of the cyanide salt. Monitoring the reaction by ${ }^{31} \mathrm{P}\left\{{ }^{1} \mathrm{H}\right\} \mathrm{NMR}$ spectroscopy revealed the clean formation of [(PHDI)Co$\left.\left(\eta^{3}-\mathrm{P}_{3}\right)(\mathrm{CN})\right]^{-}(\mathbf{5}$; singlet at $\delta=-193.2 \mathrm{ppm})$, which is a very rare example of an anionic cyclo- $\mathrm{P}_{3}$ cobalt complex. ${ }^{[16]}$ The tetra- $n$-butylammonium salt $\left[n \mathrm{Bu}_{4} \mathrm{~N}\right] \mathbf{5}$ can be isolated in 40 $64 \%$ yield by crystallization from toluene. Compared to related neutral species such as $\left[(\mathrm{ArNC})_{3} \mathrm{Co}\left(\eta^{3}-\mathrm{P}_{3}\right)\right](\mathrm{Ar}=2,6-$ (Mes $\left.)_{2} \mathrm{C}_{6} \mathrm{H}_{3}, \delta=-276 \mathrm{ppm}\right),{ }^{[17]}$ and $\left[\left(\mathrm{CH}_{3} \mathrm{C}\left(\mathrm{CH}_{2} \mathrm{PPh}_{2}\right)_{3}\right) \mathrm{Co}-\right.$ $\left.\left(\eta^{3}-\mathrm{P}_{3}\right)\right](\delta=-278 \mathrm{ppm}),{ }^{[18]}$ the ${ }^{31} \mathrm{P}\left\{{ }^{1} \mathrm{H}\right\}$ NMR resonance of $\left[n \mathrm{Bu}_{4} \mathrm{~N}\right] \mathbf{5}(\delta=-193.2 \mathrm{ppm})$ is shifted downfield. In addition,

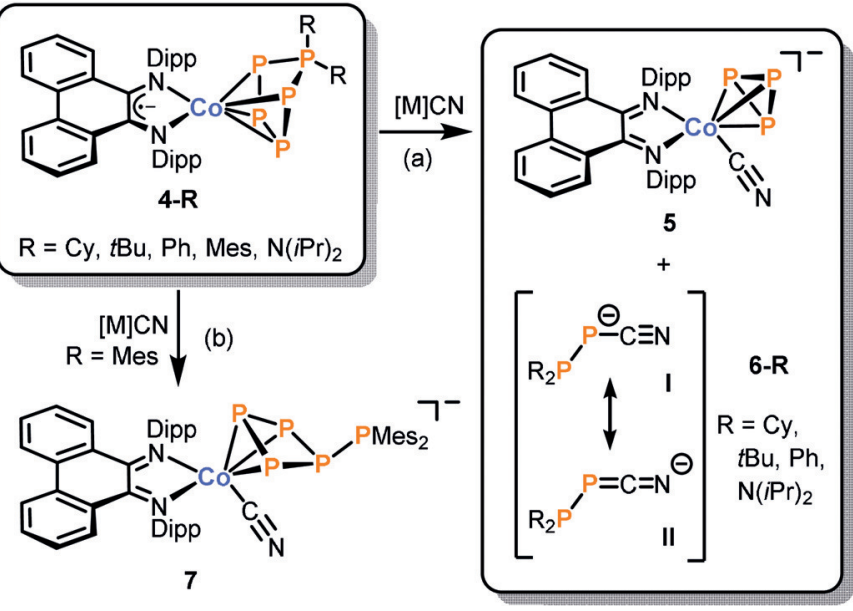

Scheme 4. a) Fragmentation and b) rearrangement of the pentaphosphido ligand in 4-R depending on the substituent R. Reagents and byproducts: a) for $\mathrm{R}=\mathrm{Cy}, t \mathrm{Bu}, \mathrm{Ph}, \mathrm{N}(\mathrm{iPr})_{2}:+2$ equiv [M]CN; b) only for $\mathrm{R}=$ Mes: +1 equiv $[\mathrm{M}] \mathrm{CN}\left([\mathrm{M}]=\left[n \mathrm{Bu}_{4} \mathrm{~N}\right]^{+},\left[\mathrm{Et}_{4} \mathrm{~N}\right]^{+},[\mathrm{K}(18 \mathrm{c}-6)]^{+}\right) . \mathrm{I}$ and II are two conceivable resonance structures of anions 6-R.

the formation of the new cyanodiphoshanide anions $\left[\mathrm{R}_{2} \mathrm{PPCN}\right]^{-}\left(\mathbf{6}-\mathbf{R}, \mathrm{R}=\mathrm{Cy}, t \mathrm{Bu}, \mathrm{Ph}, \mathrm{N}(i \mathrm{Pr})_{2}\right)$ was observed, which were identified by the characteristic set of doublets $\left({ }^{1} J_{\mathrm{PP}}=261\right.$ to $\left.278 \mathrm{~Hz}\right)$ in the ${ }^{31} \mathrm{P}\left\{{ }^{1} \mathrm{H}\right\}$ NMR spectra.

The reaction thus results in an unusual fragmentation of the polyphosphide ligand into a $\mathrm{P}_{3}$ and a $\mathrm{P}_{2}$ unit. To our knowledge, there is only one related reaction involving the $[3+2]$ fragmentation of a $\mathrm{P}_{5}$ species in the literature, which has a completely different outcome. As reported by Weigand and co-workers, the reaction of the $\left[\mathrm{P}_{5} \mathrm{DippCl}\right]^{+}$cation $(\mathrm{Dipp}=$ 2,6-diisopropylphenyl) with $N, N^{\prime}$-bis(2,6-diisopropylphenyl)4,5-dichloroimidazolin-2-ylidene ( $\left.\mathrm{IPrCl}_{2}\right)$ affords a triphosphaallyl cation $\left[\mathrm{P}_{3}\left(\mathrm{IPrCl}_{2}\right)_{2}\right]^{+}$and a neutral $\mathrm{P}_{2}$ species $\left[\left(\mathrm{IPrCl}_{2}\right) \mathrm{PP}(\mathrm{Cl}) \mathrm{Dipp}\right] .{ }^{[19]}$

$\left[n \mathrm{Bu}_{4} \mathrm{~N}\right] 6-\boldsymbol{t} \mathrm{Bu}$ can be isolated as a light-purple solid in $40 \%$ yield by extracting the crude reaction mixture with cyclohexane $/ n$-hexane $(3: 2 \mathrm{v} / \mathrm{v})$.

Although X-ray quality crystals of $\left[n \mathrm{Bu}_{4} \mathrm{~N}\right] \mathbf{5}$ and $\left[n \mathrm{Bu}_{4} \mathrm{~N}\right]$ 6- $t \mathrm{Bu}$ could not be obtained so far, the single-crystal $\mathrm{X}$-ray structures of the two potassium salts $[\mathrm{K}(18 \mathrm{c}-6)] \mathbf{5}$ and $[\mathrm{K}(18 \mathrm{c}-6)] \mathbf{6 - t} \mathbf{B u}$ (Figure 2) have been obtained from separate single crystals grown from the same reaction mixture (attempts to separate these compounds on a preparative scale have so far been unsuccessful). The molecular structure of $[\mathrm{K}(18 \mathrm{c}-6)] \mathbf{5}$ features a cobalt atom coordinated by a cyanide anion, a formally neutral PHDI ligand [C1-N1 $1.338(2), \mathrm{C} 2-\mathrm{N} 2$ 1.344(2), and $\mathrm{C} 1-\mathrm{C} 2$ 1.453(2) $\AA]^{[20]}$ and a $\eta^{3}$-coordinated cyclo- $\mathrm{P}_{3}$ ring.

The mean $\mathrm{P}-\mathrm{P}(2.1361(8) \AA)$ and $\mathrm{Co}-\mathrm{P}(2.300(5) \AA)$ bond lengths in $[\mathrm{K}(18 \mathrm{c}-6)] \mathbf{5}$ are similar to those in neutral $\mathrm{CoP}_{3}$ complexes. ${ }^{[16-18,21]}$ The Co-C (1.909(2) $\AA$ ) and $\mathrm{C} \equiv \mathrm{N}$ (1.153(2) $\AA$ ) bond lengths of the cyanide ligand as well as the $\mathrm{CN}$ stretching frequency $\left(\tilde{v}=2068 \mathrm{~cm}^{-1}\right)$ are typical for cyanidecobalt complexes. ${ }^{[22]}$ The solid-state molecular structure of [K(18c-6)]6-tBu shows an almost linear, phosphanyl-substituted PCN moiety (P1-C1-N1 $\left.178.4(1)^{\circ}\right)$ with a $\mathrm{P}-\mathrm{P}$ distance of 2.1895(4) $\AA$, that is, close to a typical single bond. ${ }^{[13]}$ The 


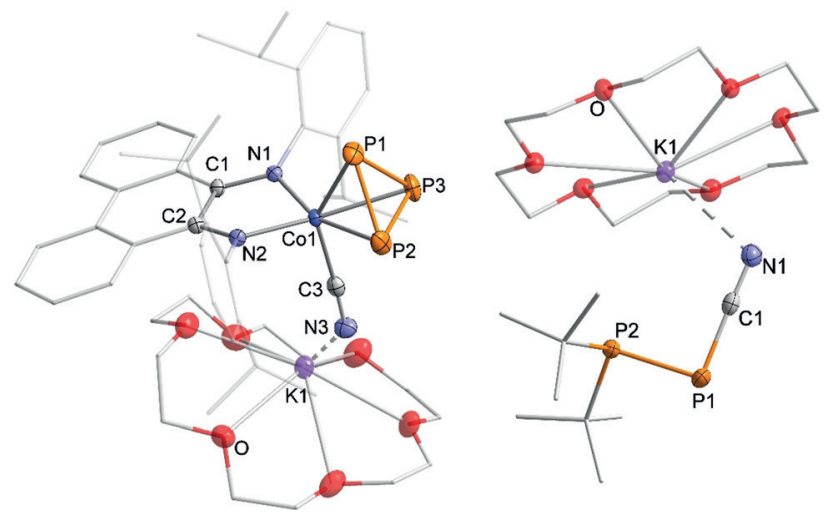

Figure 2. Solid-state molecular structures of $[\mathrm{K}(18 \mathrm{c}-6)]\left[(\mathrm{PHDI}) \mathrm{Co}\left(\eta^{3}\right.\right.$ $\left.\left.\mathrm{P}_{3}\right)(\mathrm{CN})\right]$ (left, [K(18c-6)]5) and [K(18c-6)][tBu$\left.{ }_{2} \mathrm{PPCN}\right]$ (right, [K(18c-6)]6$t \mathrm{Bu})$. Hydrogen atoms, solvent molecules, and disorder are omitted for clarity and thermal ellipsoids are drawn at the $50 \%$ probability level. Selected bond lengths $[\AA]$ and angles $\left[^{\circ}\right]$ : [K(18c-6)]5: P1-P2 2.1256(8), P1-P3 2.1228(7), P2-P3 2.1599(7), Co1-P1 2.2780(5), Co1-P2 2.3200(5), Co1-P3 2.3027(5), Co1-N1 1.908(1), Co1-N2 $1.906(2), \mathrm{Co} 1-\mathrm{C} 31.909(2), \mathrm{C} 1-\mathrm{N} 11.338(2), \mathrm{C} 2-\mathrm{N} 21.344(2), \mathrm{C} 3-\mathrm{N} 3$ $1.153(2), \mathrm{C} 1-\mathrm{C} 21.453(2), \mathrm{K} 1 \cdots \mathrm{N} 32.714(2)$; P1-P2-P3 59.38(2), P1-P3 P2 59.51(2), P2-P1-P3 61.12(2), Co1-C3-N3 177.0(2); [K(18c-6)]6-tBu: P1-P2 2.1895(4), P1-C1 1.763(1), C1-N1 1.160(2), K1N1 2.828(1); P1-C1-N1 178.4(1), C1-P1-P2 92.43(4).

structural motif is reminiscent of the anions $\left[\mathrm{P}(\mathrm{CN})_{2}\right]^{-}$and $[\mathrm{PhPCN}]^{-}$reported by Schmidpeter et al. ${ }^{[23-25]}$ The IR spectrum shows the characteristic $v_{\mathrm{CN}}$ stretch at $\tilde{v}=2049 \mathrm{~cm}^{-1}$, which is lower than those of known dicyanophosphanides $\left[\mathrm{P}(\mathrm{CN})_{2}\right]^{-} \quad\left(\tilde{v}=2120,2113 \mathrm{~cm}^{-1}\right)^{[23,24]}$ and other trivalent monocyanophosphanes $\left(\tilde{v} \approx 2160 \mathrm{~cm}^{-1}\right)$. ${ }^{[26]}$

Recently, Borger, Grützmacher, and co-workers described related cyanodiphosphanides [(NHP)PCN] with bulky $N$-heterocyclic phosphenium (NHP) substituents. ${ }^{[7]}$ These species feature a similar $\mathrm{CN}$ stretching frequency $\left(\tilde{v}=2087\right.$ to $\left.2046 \mathrm{~cm}^{-1}\right)$ and similar bond parameters as $[\mathrm{K}(18 \mathrm{c}-6)] \mathbf{6}-\boldsymbol{t} \mathbf{B} \mathbf{u}^{\left[{ }^{7,23-25]}\right.}$ Analogous to the compounds reported by Grützmacher and co-workers, the electronic structure of 6 $\mathbf{R}$ may be described as both a cyanophosphanide $\left(\mathrm{R}^{\prime} \mathrm{P}^{-}-\mathrm{C} \equiv \mathrm{N}\right.$, $\left.\mathbf{I}, \mathrm{R}^{\prime}=\mathrm{PR}_{2}\right)$ and a phosphaketeneimide $\left(\mathrm{R}^{\prime} \mathrm{P}=\mathrm{C}=\mathrm{N}^{-}, \mathbf{I I}, \mathrm{R}^{\prime}=\right.$ $\mathrm{PR}_{2}$ ) resonance structure (c.f. Scheme 4, pathwaya). A natural resonance analysis at the $\mathrm{B} 3 \mathrm{LYP} / 6-31 \mathrm{G}+{ }^{*}$ level shows that the phosphaketeneimide form plays only a minor role in the electronic ground state of 6-tBu (I: $69 \%$ versus II: $23 \%)$. Analogous calculations on related cyanate and phosphaethynolate anions $\left(\mathrm{O}^{-}-\mathrm{C} \equiv \mathrm{X}\right.$ versus $\left.\mathrm{O}=\mathrm{C}=\mathrm{X}^{-}, \mathrm{X}=\mathrm{N}, \mathrm{P}\right)$ gave much higher contributions of the ketene form in $\mathrm{NCO}^{-}$ $(33 \%)$ and $\mathrm{PCO}^{-}(40 \%){ }^{[27]}$

Remarkably, a different product, $\left[\mathrm{Et}_{4} \mathrm{~N}\right]\left[(\mathrm{PHDI}) \mathrm{Co}\left(\eta^{3}-\right.\right.$ $\left.\left.\mathrm{P}_{4} \mathrm{PMes}_{2}\right)(\mathrm{CN})\right]\left(\left[\mathrm{Et}_{4} \mathrm{~N}\right] 7\right)$, was isolated when the mesitylsubstituted complex 4-Mes was reacted with $\left[\mathrm{Et}_{4} \mathrm{~N}\right] \mathrm{CN}$ (one equiv, Scheme 4, pathwayb). Monitoring the reaction by ${ }^{31} \mathrm{P}\left\{{ }^{1} \mathrm{H}\right\}$ NMR spectroscopy showed the reaction reaches full conversion within two hours at $-30^{\circ} \mathrm{C}$ in $\mathrm{MeCN}$; the main product, $\left[\mathrm{Et}_{4} \mathrm{~N}\right] 7$, was identified by an $\mathrm{AB}_{2} \mathrm{CD}$ spin system $(\delta=32.8,59.2,94.0$, and $193.7 \mathrm{ppm})$. Deep-purple crystals were isolated in $38 \%$ yield from toluene/THF after work-up at low temperature $\left(<-30^{\circ} \mathrm{C}\right) \cdot{ }^{[28]}$ A single-crystal XRD structure (Figure 3) shows a bent $\mathrm{P}_{4}$ ring coordinating to a cobalt center through three $\mathrm{P}$ atoms with $\mathrm{P} 3-\mathrm{P} 4$ and $\mathrm{P} 4-\mathrm{P} 5$ bond lengths of 2.1667(9) and 2.172(1) A, respectively, thus indicating some delocalized character. The remaining $\mathrm{P}-\mathrm{P}$ bond lengths (2.2416(9), 2.241(1), and 2.2381(9) $\AA$ ) are typical for single bonds. ${ }^{[13,29]}$ The structural parameters of the PHDI ligand (C1-N1 1.328(4), C2-N2 1.335(3), and C1C2 $1.457(4) \AA$ ) are similar to those of $[\mathrm{K}(18 \mathrm{c}-6)] \mathbf{5}$, which suggests the presence of a neutral PHDI molecule. ${ }^{[20]}$

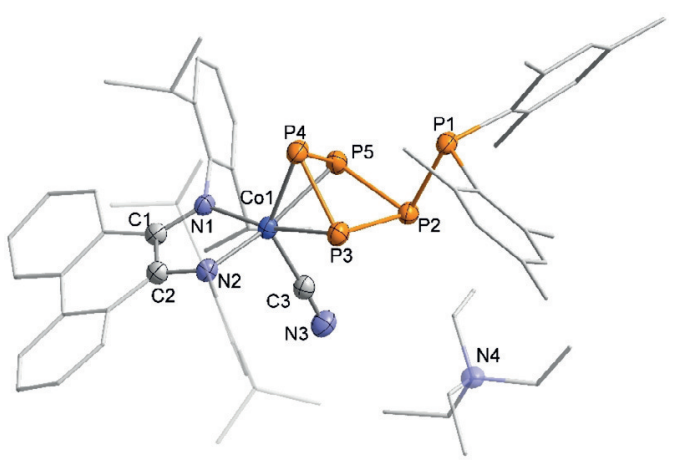

Figure 3. Solid-state molecular structure of $\left[\mathrm{Et}_{4} \mathrm{~N}\right]\left[(\mathrm{PHDI}) \mathrm{Co}\left(\eta^{3}\right.\right.$ $\left.\left.\mathrm{P}_{4} \mathrm{PMes}_{2}\right)(\mathrm{CN})\right]\left(\left[\mathrm{Et}_{4} \mathrm{~N}\right] 7\right)$. Hydrogen atoms are omitted for clarity and thermal ellipsoids are drawn at the $50 \%$ probability level. Selected bond lengths $[\AA \AA]$ and angles [ $\left.{ }^{\circ}\right]$ : P1-P2 2.2416(9), P2-P3 2.241 (1), P2-P5 2.2381(9), P3-P4 2.1667(9), P4-P5 2.172(1), Co1-P3 2.3356(8), Co1-P4 2.2671 (8), Col-P5 2.3174(8), Col-N1 1.921 (2), Col-N2 $1.927(2), \mathrm{Co} 1-\mathrm{C} 31.925(3), \mathrm{C} 1-\mathrm{N} 11.328(4), \mathrm{C} 2-\mathrm{N} 21.335(3), \mathrm{C} 3-\mathrm{N} 3$ $1.144(4)$, C1-C2 1.457(4); P1-P2-P3 94.77(4), P1-P2-P5 98.13(3), P2-P3P4 90.36(4), P3-P4-P5 83.68(4), P4-P5-P2 90.28(4), P5-P2-P3 80.52(3).

The mechanism for the formation of $\left[\mathrm{Et}_{4} \mathrm{~N}\right] 7$ is proposed to involve an attack of the cyanide anion on the cobalt center, which induces a rearrangement to a phosphanyl-substituted cyclo- $\mathrm{P}_{4}$ ring. Note that $\left[\mathrm{Et}_{4} \mathrm{~N}\right] 7$ is not converted into $\mathrm{P}_{3}$ and $\mathrm{P}_{2}$ products (5 and hypothetical 6-Mes) by the addition of a second equivalent of cyanide. Presumably, the bulky mesityl substituents prevents the $\mathrm{CN}^{-}$anion from approaching P2. It is very likely that intermediates similar to $\left[\mathrm{Et}_{4} \mathrm{~N}\right] 7$ are formed in the fragmentation reactions of $\mathbf{4 - R}$ with smaller substituents.

In conclusion, neutral pentaphosphido complexes 4-R with an unprecedented range of alkyl, aryl, and amino substituents are readily accessible from $[\mathrm{K}(18 \mathrm{c}-6)] \mathbf{1}, \mathrm{P}_{4}$, and $\mathrm{R}_{2} \mathrm{PCl}$ in two steps. The pentaphosphorus ligands of $\mathbf{4 - R}$ undergo a remarkable [3+2] fragmentation upon reaction with two equivalents of cyanide, thereby forming the anionic cyclotriphosphido cobalt complex $\mathbf{5}$ and phosphanyl-substituted cyanodiphosphanides 6-R. The reaction of 4-Mes with cyanide affords $\left[\mathrm{Et}_{4} \mathrm{~N}\right] \mathbf{7}$, which contains a rearranged $\mathrm{P}_{5} \mathrm{Mes}_{2}$ ligand. The structure of this complex suggests that cyclotetraphosphido complexes are key intermediates en route to anions $\mathbf{5}$ and 6-R. The results of this work show that diimine cobalt complexes are excellent platforms for studying the degradation of polyphosphorus ligands with inorganic nucleophiles. An extension of this approach to a wider range of polyphosphides and other nucleophiles should give rise to other unusual phosphorus compounds. In addition, reactions 
of $[\mathrm{K}(18 \mathrm{c}-6)] \mathbf{2}$ and $\left[n \mathrm{Bu}_{4} \mathrm{~N}\right] \mathbf{5}$ with electrophiles will likely give rise to unusual polyphosphanes and polyphosphanido complexes. Investigations into this research area are currently underway.

\section{Acknowledgements}

Financial support by the Deutsche Forschungsgemeinschaft (WE4621/3-1 and WO1496/7-1), the European Research Council (CoG 772299), the Stiftung der Deutschen Wirtschaft (sdw, fellowship to C.M.H.), and the Fonds der Chemischen Industrie (fellowship to T.M.M.) is gratefully acknowledged. We thank Dr. Stefanie Gärtner for crystallographic assistance as well as Dr. Daniel J. Scott and Dr. John Kelly (all University of Regensburg) for helpful comments on the manuscript.

\section{Conflict of interest}

The authors declare no conflict of interest.

Keywords: cobalt · cyanides - phosphorus - pnictides . redox-active ligands

How to cite: Angew. Chem. Int. Ed. 2019, 58, 18931-18936 Angew. Chem. 2019, 131, 19107-19112

[1] a) B. M. Cossairt, N. A. Piro, C. C. Cummins, Chem. Rev. 2010 110, 4164-4177; b) M. Scheer, G. Balázs, A. Seitz, Chem. Rev. 2010, 110, 4236-4256; c) M. Caporali, L. Gonsalvi, A. Rossin, M. Peruzzini, Chem. Rev. 2010, 110, 4178-4235.

[2] a) A. Velian, C. C. Cummins, Chem. Sci. 2012, 3, 1003; b) P. Barbaro, A. Ienco, C. Mealli, M. Peruzzini, O. J. Scherer, G. Schmitt, F. Vizza, G. Wolmershäuser, Chem. Eur. J. 2003, 9 , $5195-5210$; c) S. Pelties, A. W. Ehlers, R. Wolf, Chem. Commun. 2016, 52, 6601-6604; d) E. Mädl, M. V. Butovskii, G. Balázs, E. V. Peresypkina, A. V. Virovets, M. Seidl, M. Scheer, Angew. Chem. Int. Ed. 2014, 53, 7643-7646; Angew. Chem. 2014, 126 , 7774-7777; e) P. Barbaro, C. Bazzicalupi, M. Peruzzini, S. Seniori Costantini, P. Stoppioni, Angew. Chem. Int. Ed. 2012 51, 8628-8631; Angew. Chem. 2012, 124, 8756-8759.

[3] G. Capozzi, L. Chiti, M. Di Vaira, M. Peruzzini, P. Stoppioni, J. Chem. Soc. Chem. Commun. 1986, 1799-1800.

[4] B. M. Cossairt, M.-C. Diawara, C. C. Cummins, Science 2009, $323,602$.

[5] A. E. Seitz, M. Eckhardt, A. Erlebach, E. V. Peresypkina, M. Sierka, M. Scheer, J. Am. Chem. Soc. 2016, 138, 10433-10436.

[6] C. G. P. Ziegler, T. M. Maier, S. Pelties, C. Taube, F. Hennersdorf, A. W. Ehlers, J. J. Weigand, R. Wolf, Chem. Sci. 2019, 10, $1302-1308$.

[7] Z. Li, J. E. Borger, F. Müller, J. R. Harmer, C.-Y. Su, H. Grützmacher, Angew. Chem. Int. Ed. 2019, 58, 11429-11433; Angew. Chem. 2019, 131, 11551-11555.

[8] S. Pelties, T. Maier, D. Herrmann, B. de Bruin, C. Rebreyend, S. Gärtner, I. G. Shenderovich, R. Wolf, Chem. Eur. J. 2017, 23, 6094-6102.

[9] A. Cavaillé, N. Saffon-Merceron, N. Nebra, M. Fustier-Boutignon, N. Mézailles, Angew. Chem. Int. Ed. 2018, 57, 1874 1878; Angew. Chem. 2018, 130, 1892-1896.

[10] U. Chakraborty, J. Leitl, B. Mühldorf, M. Bodensteiner, S. Pelties, R. Wolf, Dalton Trans. 2018, 47, 3693-3697.
[11] a) O. J. Scherer, R. Winter, G. Wolmershuser, Z. Anorg. Allg. Chem. 1993, 619, 827-835; b) O. J. Scherer, J. Vondung, G. Wolmershäuser, Angew. Chem. Int. Ed. Engl. 1989, 28, $1355-$ 1357; Angew. Chem. 1989, 101, 1395-1397; c) M. Herberhold, G. Frohmader, W. Milius, J. Organomet. Chem. 1996, 522, 185-196; d) K. A. Mandla, C. E. Moore, A. L. Rheingold, J. S. Figueroa, Angew. Chem. Int. Ed. 2019, 58, 1779-1783; Angew. Chem. 2019, 131, 1793-1797; e) K. A. Mandla, M. L. Neville, C. E. Moore, A. L. Rheingold, J. S. Figueroa, Angew. Chem. Int. Ed. 2019, 58, 15329-15333; Angew. Chem. 2019, 131, 15473-15477.

[12] F. Dielmann, A. Timoshkin, M. Piesch, G. Balázs, M. Scheer, Angew. Chem. Int. Ed. 2017, 56, 1671-1675; Angew. Chem. 2017, 129, 1693-1698.

[13] For calculated single- and double-bond lengths, see P. Pyykkö, M. Atsumi, Chem. Eur. J. 2009, 15, 12770-12779.

[14] B. Gao, X. Luo, W. Gao, L. Huang, S.-m. Gao, X. Liu, Q. Wu, Y. Mu, Dalton Trans. 2012, 41, 2755-2763.

[15] For the use of cyanide to release polyphosphorus molecules from a copper(I) iodide matrix, see A. Pfitzner, M. F. Bräu, J. Zweck, G. Brunklaus, H. Eckert, Angew. Chem. Int. Ed. 2004, 43, $4228-$ 4231; Angew. Chem. 2004, 116, 4324-4327.

[16] While this manuscript was under review, a related anionic complex $\left.(\mathrm{MeNHC})_{2} \mathrm{P}\right]\left[\eta^{5}-\mathrm{Cp}^{t \mathrm{Bu} 3} \mathrm{Co}\left(\eta^{3}-\mathrm{P}_{3}\right)\right] \quad(\mathrm{MeNHC}=1,3,4,5-$ tetramethylimidazolin-2-ylidene) was published: M. Scheer, M. Piesch, S. Reichl, M. Seidl, G. Balázs, Angew. Chem. Int. Ed. 2019, https://doi.org/10.1002/anie.201908397; Angew. Chem. 2019, https://doi.org/10.1002/ange.201908397.

[17] C. Chan, A. E. Carpenter, M. Gembicky, C. E. Moore, A. L. Rheingold, J. S. Figueroa, Organometallics 2019, 38, 1436-1444.

[18] M. Di Vaira, L. Sacconi, P. Stoppioni, J. Organomet. Chem. 1983, $250,183-195$.

[19] M. H. Holthausen, S. K. Surmiak, P. Jerabek, G. Frenking, J. J. Weigand, Angew. Chem. Int. Ed. 2013, 52, 11078-11082; Angew. Chem. 2013, 125, 11284-11288.

[20] a) R. van Belzen, R. A. Klein, W. J. J. Smeets, A. L. Spek, R. Benedix, C. J. Elsevier, Recl. Trav. Chim. Pays-Bas 1996, 115, 275-285; b) R. van Belzen, R. A. Klein, H. Kooijman, N. Veldman, A. L. Spek, C. J. Elsevier, Organometallics 1998, 17, $1812-1825$; c) W. W. Kramer, L. A. Cameron, R. A. Zarkesh, J. W. Ziller, A. F. Heyduk, Inorg. Chem. 2014, 53, 8825-8837; d) G. A. Abakumov, N. O. Druzhkov, T. N. Kocherova, K. A. Kozhanov, A. v. Murugova, E. N. Egorova, Dokl. Chem. 2016, 467, 109-112.

[21] a) F. Cecconi, P. Dapporto, S. Midollini, L. Sacconi, Inorg. Chem. 1978, 17, 3292-3294; b) C. A. Ghilardi, S. Midollini, A. Orlandini, L. Sacconi, Inorg. Chem. 1980, 19, 301-306.

[22] a) A search of the Cambridge Crystal Structure Database (CCSD), version 5.39 update 4, 14/05/2019, revealed 96 cobalt complexes bearing only one terminal cyanide ligand with a mean $\mathrm{Co}-\mathrm{C}$ distance of $1.900 \AA$ (median $1.886 \AA$ ) and a mean $\mathrm{C} \equiv \mathrm{N}$ distance of $1.134 \AA$ (median $1.141 \AA$ ) ; b) P. Rigo, A. Turco, Coord. Chem. Rev. 1974, 13, 133-172.

[23] A. Schmidpeter, G. Burget, F. Zwaschka, W. S. Sheldrick, Z. Anorg. Allg. Chem. 1985, 527, 17-32.

[24] W. S. Sheldrick, J. Kroner, F. Zwaschka, A. Schmidpeter, Angew. Chem. Int. Ed. Engl. 1979, 18, 934-935; Angew. Chem. 1979, 91 , $998-1000$.

[25] A. Schmidpeter, K.-H. Zirzow, G. Burget, G. Huttner, I. Jibril, Chem. Ber. 1984, 117, 1695-1706.

[26] a) S. Holand, F. Mathey, Organometallics 1988, 7, 1796-1801; b) A. Fischer, I. Neda, P. G. Jones, R. Schmutzler, Phosphorus Sulfur Silicon Relat. Elem. 1993, 83, 135-148; c) A. Vollbrecht, I. Neda, A. Fischer, P. G. Jones, R. Schmutzler, Phosphorus Sulfur Silicon Relat. Elem. 1995, 107, 69-78.

[27] S. Alidori, D. Heift, G. Santiso-Quinones, Z. Benkő, H. Grützmacher, M. Caporali, L. Gonsalvi, A. Rossin, M. Peruzzini, Chem. Eur. J. 2012, 18, $14805-14811$. 
[28] [ $\left.\mathrm{Et}_{4} \mathrm{~N}\right] 7$ decomposes to $\left[\mathrm{Et}_{4} \mathrm{~N}\right] \mathbf{2}$ and $\mathrm{Mes}_{2} \mathrm{PH}$ in solution at room temperature over several days. These species were identified by their ${ }^{31} \mathrm{P}\left\{{ }^{1} \mathrm{H}\right\}$ NMR shifts: R. A. Bartlett, M. M. Olmstead, P. P. Power, G. A. Sigel, Inorg. Chem. 1987, 26, 1941-1946.

[29] Related phosphaallylic cyclo- $\mathrm{P}_{4} \mathrm{R}$ ligands are found in oligonuclear Cr, Mo, and W carbonyl complexes: a) M. Scheer, U. Becker, J. Magull, Polyhedron 1998, 17, 1983-1989; b) M.
Scheer, M. Dargatz, P. G. Jones, J. Organomet. Chem. 1993, 447, 259-264.

Manuscript received: July 14, 2019

Accepted manuscript online: October 1, 2019

Version of record online: November 7, 2019 